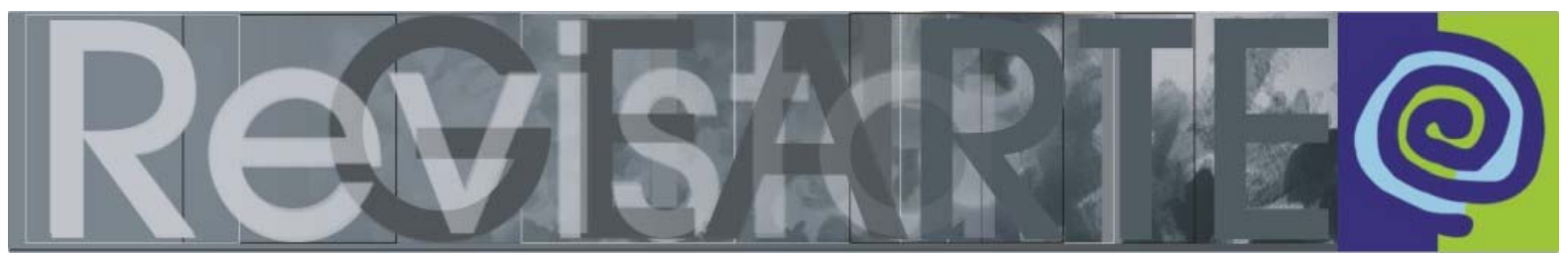

ISSN 2357-9854

\title{
Reflexões sobre a experiência estética na educação
}

\author{
Gilvânia Maurício Dias de Pontes (UFRN - Brasil)
}

\section{RESUMO}

Este artigo trata da tessitura de algumas interfaces entre as teorias de Dewey e Merleau-Ponty para apontar possíveis desdobramentos e contribuições para organização de práticas docentes que se preocupem com a educação estética de crianças. O tema da experiência estética vem se tornando recorrente nas produções contemporâneas sobre educação, Arte/Educação e educação da infância. Para abordar os significados de experiência estética, optamos por autores como Dewey e Merleau-Ponty, pois esses autores se debruçam sobre o conceito de experiência estética, considerando as relações que o sujeito estabelece em seu contato significativo no e com o mundo que o cerca. Dessa forma, no texto, buscamos trazer a dimensão estética como parte da experiência vivida que ocorre no encontro entre o sujeito e o mundo como uma contribuição significativa às práticas docentes enfatizando a educação estética de crianças.

PALAVRAS-CHAVE

Estética. Experiência estética. Práticas docentes. Educação estética de crianças.

\begin{abstract}
This article deals with the interweaving of some interfaces among the theories from Dewey and Merleau-Ponty to point out possible developments and contributions to the organization of teaching practices that worry about children's aesthetic education. The theme of aesthetic experience has become recurrent in contemporary productions on education, Arts/Education and childhood education. In order to address the meanings from aesthetic experiences, we choose authors such as Dewey and Merleau-Ponty, because these authors had studied the concept of aesthetic experience, considering the relationships that the subject establishes in significant contact in and with the world around him. Thus, in this text, we try to show the aesthetic dimension as part of living experience that occurs in the encounter between the subject and the world as a meaningful contribution to teaching practices, emphasizing the aesthetic education from children. KEYWORDS
\end{abstract}

Aesthetic. Aesthetic experience. Teaching practices. Children's aesthetic education.

\section{Introdução}

O tema da experiência estética ${ }^{1}$, contemporaneamente, tornou-se recorrente nas produções sobre educação, Arte/Educação e, mais recentemente, também nas produções que tratam de educação na infância. Mas o que envolve tal tema? Com abordar a experiência estética tecendo relações

\footnotetext{
${ }^{1}$ Este artigo traz algumas reflexões da tese de doutorado Arte na educação da infância: saberes e práticas da dimensão estética, realizada no Programa de Pós-Graduação em Educação da Universidade Federal do Rio Grande do Sul (PPGEDU/FACED/UFRGS) com Bolsa de Doutorado da Coordenação de Aperfeiçoamento de Pessoal de Nível Superior, CAPES, Brasil.
} 
com a educação? Tais questões se constituíram como ponto de partida para organização deste texto. No intento de investigar os significados atribuídos à experiência estética, optamos por autores que colocam o sujeito da experiência estética como alguém que produz sentido enquanto vivencia a experiência. Uma leitura estética do mundo e das imagens ocorre como experiência estética de encontro entre o sujeito e o objeto a ser lido, e por isso comporta todas as nuances de que a experiência é composta.

\section{Interfaces}

Autores como Dewey e Merleau-Ponty se debruçam sobre o conceito de experiência estética, considerando as relações que o sujeito estabelece em seu contato significativo no e com o mundo que o cerca. Na obra desses autores a dimensão estética é colocada como parte da experiência vivida, ultrapassando o campo de abrangência da arte. Dewey aborda a experiência estética buscando relações entre pensar e agir. Merleau-Ponty, ao enfocá-la, questiona a fragmentação entre corpo e mente.

O conceito de experiência perpassa toda a obra do filósofo norteamericano John Dewey. O autor se preocupa, sobretudo, em evitar os dualismos que polarizam experiência e natureza, prática e teoria, arte e ciência, belas artes e arte aplicada, mente e corpo, alma e matéria. Sua intenção não é a de encontrar um terceiro polo que sintetize ou concilie os dualismos, mas considerar o espaço conceitual existente entre eles. Analisando as distinções e interpretando as diferenças, Dewey esclarece os dualismos e as possíveis relações entre os polos. Na obra de Merleau-Ponty também há a preocupação com as dualidades e a intenção de não se fixar em um ou outro polo, mas de investigar o que está entre os polos. Buscamos em Dewey e Merleau-Ponty possibilidades de diálogos no que diz respeito às questões estéticas, sem nos atermos, exclusivamente, às oposições entre eles.

Dewey investiga a relação de causa e efeito na produção artística, considerada sob a ótica do produtor e do apreciador. Ele considera tanto o processo quanto o produto da ação humana, enfatizando a relação entre os meios e os fins. Debruça-se sobre o movimento de construção e de apreciação 
da arte, explicitando a inserção da expressão e da emoção na experiência estética.

Dewey concebe a experiência como interação do sujeito com as condições que o rodeiam; desse modo, a experiência tem um caráter prático e articula-se com a vida e com a cultura. Para o autor, o pensamento não se desvincula das situações práticas do cotidiano. O autor relaciona pensamento e experiência aos acontecimentos cotidianos que instigam crianças e/ou adultos à resolução de problemas e à produção de conhecimentos.

A atividade humana, direcionada pela reflexão, permite o enlace entre pensamento e experiência. Na experiência, ocorrem alterações simultâneas entre o agente do conhecimento e o que foi conhecido, porque há modificações nas relações entre eles. Assim, agir e experimentar o conhecimento constitui o processo de aprendizagem e, nesse esforço, o sujeito passa por transformações. Transforma a si mesmo, o conhecimento e o meio em que atua.

Nessa concepção, experiência e educação estão relacionadas organicamente. A educação, entendida como um fenômeno direto e particular da vida humana, é processo de reconstrução e de reorganização do conhecimento que provoca o sujeito para experiências futuras. A educação é a experiência em curso, ao mesmo tempo em que é resultado da experiência.

Diante disso, se faz necessário pensar sobre a seleção de experiências que o educador vai reconstruir com as crianças porque experiência e educação não são diretamente equivalentes uma à outra; nem toda experiência é igualmente educativa; algumas experiências podem ser 'deseducativas'. A esse respeito, Dewey (2010a, p. 27) observa que: "Qualquer experiência que tenha o efeito de impedir ou distorcer o amadurecimento para futuras experiências é 'deseducativa'”. Desse modo, para ser educativa, uma experiência requer que se operem escolhas em que seja observada a direção da experiência.

A experiência educativa caracteriza-se por um continuum experiencial em que toda ação praticada e/ou sofrida afeta a qualidade das experiências futuras; 
isso porque gera hábitos e atitudes que estarão presentes na atuação do sujeito em experiências subsequentes.

Toda experiência é uma força em movimento que pode incitar o desejo de crescimento em experiências futuras ou pode estagnar esse crescimento em determinado momento de desenvolvimento. A tarefa do adulto educador é a de saber para que e para onde se move a experiência. Para tanto, ele é desafiado a conciliar o controle externo com a intenção de crescimento a partir da situação experienciada, o que requer interação com os sujeitos da experiência, percebendo as nuances contextuais que os envolvem. Assim, experiência e interação são conceitos inseparáveis no intuito de provocar tal crescimento. O processo educativo ocorre pela interação entre a criança, ser em desenvolvimento, os valores e as ideias presentes na cultura.

Em relação à arte, Dewey (2010b) constata que há um distanciamento entre o ideal e o real, distanciamento entre o produto da arte e a experiência que o originou. O autor alerta para o fato de que as convenções que cercam o produto artístico o têm isolado das condições humanas em que foi criado e das consequências que ele gera na experiência real da vida. Acrescenta que, para compreender o significado dos produtos artísticos, é preciso recorrer às forças e condições comuns da experiência que não se costumam considerar estéticas. Conforme o autor,

As origens da arte na experiência humana serão apreendidas por quem vir como a graça tensa do jogador de bola contagia a multidão de espectadores; por quem notar o deleite da dona de casa que cuida de suas plantas e o interesse atento com que seu marido cuida do pedaço de jardim em frente à casa (DEWEY, 2010b, p. 62).

Dewey pretende recuperar a continuidade entre as experiências estéticas e o curso da vida cotidiana quando alerta para o envolvimento do sujeito, aquele que atua e sofre a experiência, como alguém que, ao atuar, aprecia o produto de sua atuação. A partir dessa constatação, Dewey questiona: o que há de estético nas experiências rotineiras e o que caracteriza uma experiência estética?

Ao abordar o aspecto estético das experiências e as experiências estéticas, Dewey ressalta a condição de continuidade e enfatiza o aspecto 
consumatório da experiência ao afirmar que, com frequência, a experiência que se tem é incompleta porque há distração e dispersão, o que faz com que ela não alcance o fim para o qual foi iniciada; há a cessação. Para ele "temos uma experiência singular quando o material vivenciado faz o percurso até a sua consecução. Então, e só então, ela é integrada e demarcada no fluxo geral da experiência proveniente de outras experiências" (DEWEY, 2010b. p. 109-110).

Para Dewey, a teoria estética deveria lastrear-se pelo pressuposto de que o estético não está fora da experiência; ele faz parte do desenvolvimento de toda experiência para que essa tenha completude. Dessa forma, o artístico, como ato de produção, e o estético, como ato de percepção e prazer, são dimensões indissociáveis no ato criativo.

Referindo-se à arte, Dewey critica a separação entre os termos estético e artístico, lamentando não haver, na língua inglesa, uma palavra que signifique a união desses dois termos. $\mathrm{O}$ artístico é entendido como um processo de fazer ou criar, enquanto o estético relaciona-se à experiência como apreciação, percepção e deleite. Assim concebidos, os termos denotam uma divisão entre produtor e consumidor, entre agir e sofrer a experiência. Tal separação entre o artístico e o estético não se sustenta quando exemplificada em experiências de criação no campo da arte.

Para Dewey o movimento do artista para transmutar o objeto em arte exige que relacione o fazer e a apreciação, pois a percepção estética é delimitadora da concepção de arte, estando diretamente ligada à atividade de produção e de recepção do produto.

O processo da arte como produção está relacionado organicamente com o estético na percepção. Na produção, atuam sentidos como visão, tato, olfato e paladar que se tornam estéticos ao classificar o que é percebido. A atuação dos sentidos, para produzir significado para experiência, não é mecânica, "a mão e o olho, quando a experiência é estética, são apenas instrumentos pelos quais opera toda a criatura viva, impulsionada e atuante todo o tempo" (DEWEY, 2010b. p. 131). 
Assim como na produção, também na recepção de arte o leitor se vê envolvido por questões que the sugerem retomar, ao seu modo, a continuidade da experiência, estabelecendo relações entre o que é visto e seu processo de produção. A recepção em si também é uma experiência construída organicamente por meio dos sentidos. Receptividade não é passividade; a recepção é algo que move organicamente, que modifica, que envolve perceber com mais profundidade; é diferente do reconhecimento que apenas rotula sem envolvimento e agitação orgânicos.

Dewey parte da ideia de experiência em sentido amplo, referente aos processos conscientes realizados pelos humanos. Essa experiência é resultado de interações do sujeito com seu meio, de forma que amplia os significados que os humanos atribuem ao seu entorno.

Embora as experiências sejam diferentes com significados diversos, há um padrão comum presente em todas as experiências, no que se refere a resultar da interação entre as criaturas e o mundo. A experiência se dá no encontro entre o eu e o objeto, em que a "interação dos dois constitui a experiência total vivenciada, e o encerramento que a conclui é a instituição de uma harmonia sentida" (DEWEY, 2010b, p. 122).

A dimensão estética da experiência, seja na arte ou nas experiências rotineiras, possibilita o vínculo entre a finitude e o processo da experiência. Torna possível a relação entre processo e produto, em que cada etapa é importante no continuum da experiência e contribui para sua consumação. A dimensão estética da experiência, por possibilitar o continuum experiencial, define a experiência como educativa.

A abordagem estética de Dewey acaba por nos remeter a um campo mais abrangente que a estética na arte; remete-nos à dimensão estética do viver cotidiano. O sujeito da experiência estética mobiliza-se organicamente para produzir sentidos por meio da percepção. A disposição à receptividade que marca a concepção de percepção estética em Dewey requer o envolvimento corporal com a matéria numa interação em que sofrer e agir sobre as coisas do mundo se integram produzindo sentidos. A percepção estética requer um 
aprendizado que possibilite ao espectador ou observador produzir sentidos em interação com os objetos.

Ao criar sua experiência de percepção estética o espectador ou observador pode experimentar relações semelhantes às vivenciadas pelo produtor. O espectador ou observador recria o percurso do produtor de acordo com seu ponto de vista e interesses.

Referindo-se ao lugar ocupado pela expressão na experiência, Dewey considera a expressão tanto em seu processo de construção, isto é, como ato, quanto como um resultado. A expressão como ato começa com uma impulsão. Impulsão é diferente de impulso: enquanto o impulso pode ser especializado, particular e mesmo instintivo, a impulsão é o movimento de todo organismo para fora e para adiante. Impulsão mobiliza o organismo em sua inteireza e, por isso, constitui o estágio inicial de toda experiência completa.

A expressão não é somente transbordamento de impulsos, requer relação entre a experiência atual e as experiências passadas, requer movimento e reflexão e, dessa forma, o simples ato de dar vazão a uma impulsão não constitui uma expressão. Na expressão, aquilo que se avoluma na experiência precisa ser esclarecido, ordenado e incorporado às experiências anteriores para que se torne expressivo.

Como vimos em Dewey também para Merleau-Ponty a distinção entre estético e artístico não se constitui como oposição, pois, sendo a estética uma dimensão do mundo vivido, está presente na arte como em outros temas.

Merleau-Ponty, assim como Dewey, considera a estética como dimensão do mundo vivido, mas o faz enfatizando a importância da percepção e do corpo na relação sujeito-objeto. Assim, a experiência estética é abordada como interação entre sujeito e mundo, considerando que o sujeito é corpo reflexionante o qual produz sentidos para sua experiência no mundo e que se expressa por meio de linguagens. Em Dewey, encontramos referências sobre a importância da continuidade da experiência em direção a uma finalidade positiva como aquilo 
que lhe constitui como educativa. Merleau-Ponty nos conduz à compreensão da interação sujeito-objeto como o que torna a experiência significativa.

Merleau-Ponty (1999) salienta que é preciso reaprender a ver o mundo numa busca de sentido do sujeito no mundo. A percepção é a experiência vivida corporalmente, a mente que percebe é uma mente encarnada. O organismo que percebe está imbricado com seu entono. O sujeito é corpo que atua numa dimensão de espaço e tempo determinado. Dessa maneira, a percepção em si mesma não existe; ela não é uma abstração ideal. A percepção só existe conforme seja vivida no mundo. Só existe enquanto incorporação da experiência vivida. Sendo assim, a experiência não provém de antecedentes ou do ambiente físico e social; ela caminha em direção a eles pelo olhar do sujeito que a vivencia.

Em Fenomenologia da Percepção (1999), o filósofo afirma que o mundo é aquilo que se vive, e não somente pensamento. Em sendo o que se vive, o mundo é inesgotável, o ser comunica-se com ele, mas não o possui. É no compartilhamento desse mundo, na coexistência com outros seres humanos, que produzimos a nós mesmos ao produzir sentido.

Para Merleau-Ponty, a experiência sensível é a base da experiência estética, isto é a experiência estética exige do sujeito uma relação com o mundo. O ser sensível é feito do mesmo estofo do mundo, isto é, ele é carne do mundo e, como tal experimenta a copresença entre corpo e mundo. O corpo como carne do mundo não é simplesmente objeto em que são impressas teorias e concepções, não é também um ser para si cuja subjetividade está voltada para o mundo interior. O ser encarnado está se produzindo nas relações com outros seres; ele habita dado espaço e tempo.

O corpo é mediador entre o ser e o mundo e, nessa mediação, ele é vidente e visível a si mesmo em simultaneidade com os outros. Os sujeitos como carne do mundo podem (com)partilhar de uma única visão e se constituir nesse processo. O sensível, enquanto simultaneidade compartilhada, pode assediar mais de um corpo, pois os corpos, embora distintos, misturam-se pelo olhar, pelo toque que produz a significação. 
O logos do mundo sensível é anterior à separação sujeito-objeto; ele é pré-reflexivo, pré-objetivo. A esse respeito, Chauí (1980, p. XI) diz que:

\begin{abstract}
A relação corpo- mundo é estesiológica: há a carne do corpo e a do mundo; há em cada um deles, uma interioridade que se propaga para o outro numa reversibilidade permanente - corpo e mundo são um campo de presença onde emergem todas as relações da vida perceptiva e do mundo sensível. Há um logos do mundo estético que torna possível a intersubjetividade como intercorporeidade, e que, através da manifestação corporal na linguagem, permite o surgimento do logos cultural, isto é do mundo humano da cultura e da história.
\end{abstract}

O logos estético, como dimensão sensível e relacional - dimensão estética da copresença entre os seres humanos -, faz parte das reflexões do filósofo sobre vários ângulos. Encontramos a experiência sensível na arte e em outros movimentos da existência. É a dimensão estética que configura o encontro entre os seres humanos. O logos estético é abordado como um tipo de racionalidade que afirma a comunicação entre a lógica e o sensível, a razão e o corpo. Essas relações encontram-se entrelaçadas na percepção e na dimensão estética.

\title{
Experiências estéticas e a educação de crianças
}

Depois dessa breve incursão pela obra de Dewey e Merleau-Ponty, em busca de significações para a expressão experiência estética, resta-nos perguntar sobre as relações entre as afirmações dos filósofos e a educação de crianças para realizar leituras estéticas da visualidade do mundo que as rodeia.

Podemos partir do princípio, compartilhado pelos dois autores, de que a criança é um ser que em seu encontro com as coisas do mundo produz sentidos. A criança é autora em seu processo de significação do mundo e, para tanto, mobiliza experiências anteriores para dar sentido ao que é vivenciado no momento presente.

Ao vivenciar experiências, a criança exercita sua capacidade leitora e expressa as relações que estabelece com aquilo com o qual entra em contato. Esse contato é corporal, isto é, no encontro com o mundo a criança mobiliza todos os sentidos para conhecer aquilo que Ihe desafia à descoberta. A criança 
experimenta cheiros, sons, sabores e texturas e diz sobre aquilo que experimentou utilizando-se de múltiplas linguagens.

Mas, as situações de leituras estéticas na infância se constituem no encontro da criança com a cultura. Esse encontro, que é corporal, pode ser mediado pelo acesso a imagens, sejam elas do cotidiano, da mídia ou das artes. Tanto em Dewey como em Merleau-Ponty a percepção é abordada como algo que sofre transformações/aprendizados, isto é, que pode ser ampliada pela vivência de novas experiências. Assim, cabe ao educador pensar sobre a articulação de experiências que ampliem o repertório cultural das crianças e que, ao mesmo tempo, considerem o seu processo perceptivo.

A partir da leitura de Dewey e Merleau-Ponty é possível observar duas abordagens da dimensão estética, que podem orientar as práticas docentes: perceber a estética como aquilo que se sente no encontro mesmo com o mundo; e observar que na educação de crianças é preciso pensar sobre a promoção de experiências estéticas que ampliem o repertório cultural e expressivo das crianças.

\section{Referências}

CHAUÍ, Marilena (Org.). Merleau-Ponty: vida e obra. In: Maurice Merleau-Ponty: textos selecionados. São Paulo: Abril Cultural,1980. p V - XIX. (Os pensadores).

DEWEY, John. Experiência e educação. Petrópolis, RJ: Vozes, 2010a.

DEWEY, John. Arte como experiência. São Paulo: Martins Fontes, 2010b.

MERLEAU-PONTY, Maurice. Fenomenologia da percepção. São Paulo: Martins Fontes, 1999.

PONTES, Gilvânia Maurício Dias de. Arte na educação da infância: saberes e práticas da dimensão estética, 2013. 327 f. Tese (doutorado) - Programa de Pós-Graduação em Educação, Universidade Federal do Rio Grande do Sul, Porto Alegre, 2013. Disponível em: <http://hdl.handle.net/10183/70604>. Acesso em 20 jul. 2015.

\section{Gilvânia Maurício Dias de Pontes}

Doutora em Educação pela Universidade Federal do Rio Grande do Sul. Mestre em Educação pela Universidade Federal do Rio Grande do Norte. Especialização em Administração Educacional pela UFRN. Graduação em Pedagogia pela UFRN. Professora Titular da Universidade Federal do Rio Grande do Norte, lotada no Núcleo de Educação da Infância, no Colégio de Aplicação. Atua na Educação Infantil e Formação de Professores.

E-mail: gilvaniapontes@hotmail.com

Currículo: http://lattes.cnpq.br/2536072255193237 